Journal for ImmunoTherapy of Cancer

To cite: Gustafson MP, Wheatley-Guy CM, Rosenthal AC, et al. Exercise and the immune system: taking steps to improve responses to cancer immunotherapy. Journal for ImmunoTherapy of Cancer 2021;9:e001872. doi:10.1136/ jitc-2020-001872

Accepted 30 May 2021

Check for updates

(c) Author(s) (or their employer(s)) 2021. Re-use permitted under CC BY-NC. No commercial re-use. See rights and permissions. Published by BMJ.

${ }^{1}$ Laboratory Medicine and Pathology, Mayo Clinic Arizona, Phoenix, Arizona, USA

${ }^{2}$ Department of Cardiovascular Diseases, Mayo Clinic Arizona, Scottsdale, Arizona, USA

${ }^{3}$ Hematology/Oncology, Mayo Clinic Arizona, Phoenix, Arizona, USA

${ }^{4}$ Pediatrics, Immunobiology, University of Arizona Medical Center - University Campus, Tucson, Arizona, USA

${ }^{5}$ Pediatrics, Immunobiology, and Nutritional Sciences, University of Arizona Medical Center University Campus, Tucson, Arizona, USA

Correspondence to Dr Michael P Gustafson; gustafson.michael@mayo.edu

\section{Exercise and the immune system: taking steps to improve responses to cancer immunotherapy}

Michael P Gustafson, ${ }^{1}$ Courtney M Wheatley-Guy, ${ }^{2}$ Allison C Rosenthal, ${ }^{3}$ Dennis A Gastineau, ${ }^{1}$ Emmanuel Katsanis, ${ }^{4}$ Bruce D Johnson, ${ }^{2}$ Richard J Simpson ${ }^{5}$

\section{ABSTRACT}

The remarkable success of cancer immunotherapies has provided new hope to cancer patients. Unfortunately, a significant proportion of patients remain unable to respond to immunotherapy or maintain durable clinical responses. The lack of objective responses likely results from profound immune dysfunction often observed in patients with cancer. There is substantial evidence that exercise and physical activity can reduce incidence and improve outcomes in cancer patients. As the immune system is highly responsive to exercise, one potential avenue to improve immune function is through exercise and physical activity. A single event of dynamic exercise results in the substantial mobilization of leukocytes with increased functional capacities into the circulation. Chronic, or longterm, exercise leads to higher physical fitness in terms of greater cardiorespiratory function and/or muscle strength and endurance. High aerobic capacity, as measured by maximal oxygen uptake, has been associated with the reduction of dysfunctional T cells and improvements in the abundance of some T cell populations. To be sure, however, the mechanisms of exercise-mediated immune changes are both extensive and diverse. Here, we examine the evidence and theorize how acute and chronic exercise could be used to improve responses to cancer immunotherapies including immune checkpoint inhibitors, dendritic cell vaccines, natural killer cell therapies, and adoptive $T$ cell therapies such as chimeric antigen receptor (CAR) T cells. Although the parameters of optimal exercise to yield defined outcomes remain to be determined, the available current data provide a compelling justification for additional human studies and clinical trials investigating the adjuvant use of exercise in immuno-oncology.

\section{INTRODUCTION}

The promise of cancer immunotherapy is rapidly transforming the field of oncology. The accumulation of vast experimental data derived from animal models and from clinical trials demonstrates that there are multiple aspects to generate successful durable clinical responses in patients receiving immunotherapy: the specificity, magnitude, and diversity of the immune response all contribute to the formation of immunological memory. One of the major obstacles to successful responses to immunotherapy is that systemic immunity in cancer patients is often impaired as a result of multiple diverse mechanisms. Emerging evidence suggests that optimal systemic immunity is critical for longer overall survival of patients with cancer and durable clinical responses to immunotherapy. ${ }^{1-3}$

A large body of evidence suggests that exercise and physical activity improves the overall health of patients with cancer and may prolong survival. ${ }^{4-7}$ Physical activity is defined as any bodily movement produced by skeletal muscles or that requires contraction of your muscles and energy expenditure. ${ }^{8}$ Exercise is a form of physical activity that involves repetitive bodily movement done in a planned and structured manner with the goal of improving or maintaining one or more components of physical health or fitness. ${ }^{9}$ Since there is such a strong association between exercise and improved outcomes in cancer patients, we suggest that a complementary approach to improving responses to immunotherapies is to strengthen systemic immunity and patient immune responses via exercise thereby allowing a more potent therapeutic response. There have been numerous studies recently published that reveal some provocative data on how exercise influences immune cell populations and their function. As such, the purpose of this review is to appraise the literature and present the scientific premise by which physical activity and exercise has the potential to restore and optimize the immune system's responses to cancer immunotherapy. Additionally, we will assess the strategy of utilizing exercise regimens to improve outcomes in patients receiving cancer immunotherapy. While we will focus primarily on human data, animal models will be discussed to shed light on potential mechanisms and to provide guidance on future investigations where there are gaps in the literature in human studies. 


\section{EXERCISE AS MEDICINE}

The use of exercise as a medicine requires an understanding of the appropriate dose of exercise to achieve the desired effect. On an individual basis, the optimal health effects of physical activity and exercise are dependent on their appropriate dose in relation to their physical fitness. ${ }^{10}$ Exercise can be performed in three general categories: acute exercise, exercise training, and chronic exercise. Acute exercise encompasses single defined events with repetitions over a short period of time. Exercise training (high intensity interval training, for example) typically involves consistent frequent events over the course of many weeks to months. Chronic exercise describes consistent and frequent exercise over a long period of time (generally over a year). While physical activity and exercise are often used interchangeably, these terms are used to reflect activities related to fitness. The term physical fitness relates to 'a set of attributes that people have or achieve that relates to the ability to perform physical activity' as defined by the US Department of Health and Human Services. Physical fitness has multiple components: cardiorespiratory fitness, muscular strength, muscular endurance, body composition and flexibility. The exercise dose is highly dependent on the FITT principles ( Frequency, Intensity, Time, and Type) and these aspects of exercise must be considered for is crucial for generating desired outcomes. ${ }^{11}$ The heterogeneous and inconsistent results that are often observed when exercise is used as medicine results from the variability of the FITT principles applied to the study design. This variability is perhaps one of the most significant problems in the exercise field and prevents simplifying the recommended amounts of exercise that are associated with physiological benefits. Fortunately, this need has been recognized as we and other groups in the field have published studies to optimize and standardize methods to better define the exercise dose in a given study. ${ }^{12-15}$

Since there are different components of exercise and fitness, the parameters to be measured should be appropriate for assessing the desired outcome. Several parameters have been used in the exercise setting and include measurements of heart rate, blood pressure, body mass index (BMI), lean body mass, work expenditure, forced expiratory volume/capacity, and maximal oxygen uptake $\left(\mathrm{VO}_{2} \max \right) . \mathrm{VO}_{2} \max$ is the gold standard for evaluating aerobic capacity/cardiorespiratory fitness and can be objectively measured during a graded cardiopulmonary exercise test with respiratory gas exchange. ${ }^{16} \mathrm{VO}_{2} \max$ is considered the best indicator of cardiorespiratory fitness and the strongest independent predictor of future survival. ${ }^{17}$ High $\mathrm{VO}_{2}$ max values are the result of higher cardiac outputs, better blood flow, better oxygen delivery, and improved mitochondrial function and volume. ${ }^{18} 19$ The assessment of physical activity can also be performed by questionnaires or surveys. Information gathered from these questions can be used to assess energy expenditure in the form of metabolic equivalent tasks. ${ }^{20}$ The incorporation of these measurements is then used to define the total exercise dose/amount/load during a given time. Depending on the study design, investigators may wish to define an acute dose that all subjects perform in a particular study or perform an assessment of a lifetime dose for correlative associations. For a further in depth discussion of the comparisons of different methodologies to quantify the exercise dose and how to put these concepts into clinical practice, we would refer the reader to an excellent review by Wasfy and Baggish. ${ }^{21}$

\section{THE IMMUNE SYSTEM IS HIGHLY RESPONSIVE TO EXERCISE}

Exercise improves immune function in part by mitigating the detrimental effects of immune dysfunction caused by both aging (immunosenescence and inflammaging), and obesity (both inflammatory and immunosuppressive mechanisms). ${ }^{22-27}$ However, exercise also induces substantial changes to both the innate and adaptive immune responses. Before these mechanisms are discussed, however, it is important to appreciate the nexus between skeletal muscle and the immune system.

\section{The myokine connection}

Muscle has been recognized as a major secretory organ ${ }^{28}$ as over 300 proteins have been identified to be secreted from resting muscle. ${ }^{29}$ As nearly half of the human body mass is composed of muscle, the muscle releases a substantial amount of proteins that regulate many physiological processes. Many of these proteins have been defined as myokines, or muscle-derived cytokines. In addition to supporting glucose metabolism and myogenic growth, these myokines mediate beneficial functions on the immune system. The most prominent myokines relevant to supporting both muscle and immune health are interleukin 4 (IL-4), IL-6, IL-7, IL-8, and IL-15. ${ }^{28}$ IL-6 released from contracting muscles rises exponentially with increasing intensity and duration of exercise to nearly 100 times the baseline plasma levels in peripheral blood. ${ }^{30} 31$ While IL-6 has both prominent proinflammatory and antiinflammatory properties, in the context of exercise, the induction of IL-6 produces an anti-inflammatory effect, without the preceding increase in tumor necrosis factor $\alpha(\mathrm{TNF} \alpha)$ levels observed in proinflammatory conditions, and functions to stimulate gluconeogenesis. ${ }^{32}$ Circulating anti-inflammatory cytokines like IL-1 receptor antagonist and IL-10 are amplified with concurrent declines in TNF- $\alpha$ because of exercise-mediated IL- 6 release. ${ }^{33}$ Chronic exercise also appears to reduce resting levels of IL-6 in circulation. ${ }^{32}$

IL-15 and IL-7, two cytokines critical for maintaining T cell homeostasis, are also highly expressed and secreted by exercising skeletal muscle. ${ }^{34}{ }^{35}$ Vigorous acute exercise leads to a strong induction of both mRNA levels and circulating plasma levels of these cytokines. ${ }^{35-37}$ IL-7 and IL-15 are critical $\mathrm{T}$ cell homeostatic cytokines that coordinate to replenish naive and memory cell populations. IL-7 provides survival and proliferative signals for recent thymic emigrants (RTE) and naïve T cells but also supports 
the generation and persistence of memory cells following antigen exposure. ${ }^{38}{ }^{39}$ IL-15 appears to primarily support the expansion of memory $\mathrm{T}$ cells and $\mathrm{CD}^{+}$memory $\mathrm{T}$ cells are particularly sensitive to IL-15. Muscle-specific ablation of IL-15 in mice led to reduced total CD8 + T cells which exhibited higher markers of exhaustion including Programmed cell death protein (PD-1), CD244, LAG-3 and TIGIT. ${ }^{40}$ Wallace et al found that IL-15 and IL-7 were both capable of promoting cell survival through upregulating antiapoptotic mechanisms and telomerase activity to preserve telomere length. The cytokines also stimulated proliferation without inducing differentiation of $\mathrm{T}$ cells by phenotypic change or acquisition of effector function. ${ }^{41}$ In support of the coordination between these two cytokines, Cieri et al found that IL-7 promotes the induction of a self-renewing, stem-cell like memory $\mathrm{CD}^{+}$ $\mathrm{T}$ cell subset $(\mathrm{Tscm})$ and IL-15 subsequently was required for the expansion of these specialized memory subsets. ${ }^{42}$ IL-15 is also critical for proper proliferation and differentiation of natural killer (NK) cells. ${ }^{43}$ The connection of muscle-derived cytokines and immune effector cell homeostasis is an area ripe for further investigation as it has been proposed that the diminished secretory output of these cytokines as a result of aging-related sarcopenia is a critical mechanism for the development of immune senescence. ${ }^{44}$ Overall, it is apparent that the induction of muscle-derived cytokines supports healthy immune effector cell populations by maintaining a proper balance of pro-inflammatory and anti-inflammatory mediators and by supporting appropriate homeostatic mechanisms.

\section{Acute exercise: increased mobilization of leucocytes}

In response to acute dynamic exercise (eg, running, cycling, rowing), there is a robust and almost instantaneous mobilization of leukocytes to the blood compartment. While granulocytes account for a large proportion of the mobilized cells, both the granulocyte to lymphocyte and monocyte to lymphocyte ratios are reduced indicating that exercise preferentially recruits lymphocytes to the bloodstream. ${ }^{45}$ There is also a preferential mobilization of lymphocyte subsets in the order of greatest magnitude of relative change-NK-cells, gamma delta $(\gamma \delta)$ T-cells, CD8+ T cells, CD4+ T cells and B-cells. ${ }^{45-47}$ Within these subsets, there also appears to be a preferential mobilization of those cell types with phenotypic characteristics of high differentiation and migration potential. ${ }^{45}$ Lymphocytes also display rapid egress kinetics with NK-cells in particular, despite increasing threefold to fivefold during the exercise, reverting to near resting levels within just a few minutes after exercise cessation. ${ }^{47}$ In the early phase of exercise recovery (eg, 1 hour after exercise cessation), blood T-cells exhibit an activated cytokinesecreting profile and NK-cells are better equipped to kill certain hematologic cancer cell lines in vitro. ${ }^{48-50}$ Similarly, $\gamma \delta$ T-cells mobilized with exercise expand more readily when stimulated with bisphosphonate antigens resulting in phenotypic shifts that promote increased cytotoxicity against a range of hematologic tumor cell lines including those derived from leukemia, lymphoma and multiple myeloma. ${ }^{51}$ The release of cytokines catecholamines and other hormones are largely involved in the mobilization, priming and/or redistribution of activated effector lymphocytes in response to acute exercise and several groups, including ours, have suggested that this acute stress response should be harnessed for therapeutic purposes such as boosting immune responses to vaccination or obtaining more potent immune cell products from the blood for cellular therapy. ${ }^{52-54}$

\section{Acute exercise: increased immune surveillance}

Since exercise redeploys massive numbers of lymphocytes with each bout, acute exercise has been purported to increase immune surveillance due to the frequent mobilization and redistribution of effector lymphocytes. This idea was best demonstrated by Pedersen et al who reported that voluntary wheel running reduced tumor incidence and growth by $\sim 60 \%$ across five different murine tumor models via mechanisms that are dependent on the catecholamine-induced mobilization and redistribution of NK-cells. ${ }^{55}$ Greater numbers of NK-cells were found in the tumors of exercised mice compared with controls, but not when mice were administered propranolol (non-selective beta-blocker) to prevent catecholamine-mediated NK-cell mobilization. Further, the exercise effects were replicated in non-exercised mice injected with daily doses of epinephrine underscoring the importance of catecholamines in facilitating immune cell mobilization and redistribution. The idea that each exercise bout contributes to improvements in antitumor immune surveillance is bolstered by a previous study from our group that T-cells mobilized into the blood with acute exercise are more responsive to ex vivo stimulation with autologous antigen presenting cells pulsed with tumor associated antigens such as the Wilms Tumor antigen (WT1), preferentially expressed antigen in melanoma (PRAME), and melanoma-associated antigen 4 (MAGE-A4) ${ }^{56}$ As such, the beneficial effects of chronic exercise may be due to the fact that immune cells are mobilized and redeployed with every exercise bout, thus improving immune surveillance without necessarily altering immune competency at the basal (ie, individual cell) level. Indeed, despite exercise-mobilized NK-cells being shown to play an important role in the antitumor effects of exercise, ${ }^{55}$ exercise training interventions in humans often results in little to no changes in NK-cell activity in vitro, ${ }^{57-59}$ although we did report recently that changes in NK-cell function might be more marked in those that show the greatest changes in aerobic fitness following the intervention. ${ }^{59}$ We should note here that most studies to date have described the effects of exercise training on 'static' endpoints of immune function using standardized in vitro based assays (eg, NK-cell cytotoxicity or T-cell proliferation using cells obtained from resting blood). We contend that immune system adaptations to exercise training might be better observed using 'dynamic' endpoints such as the number of NK-cells and 
Table 1 T cell phenotypes associated with physical conditions and improved by chronic exercise or exercise training

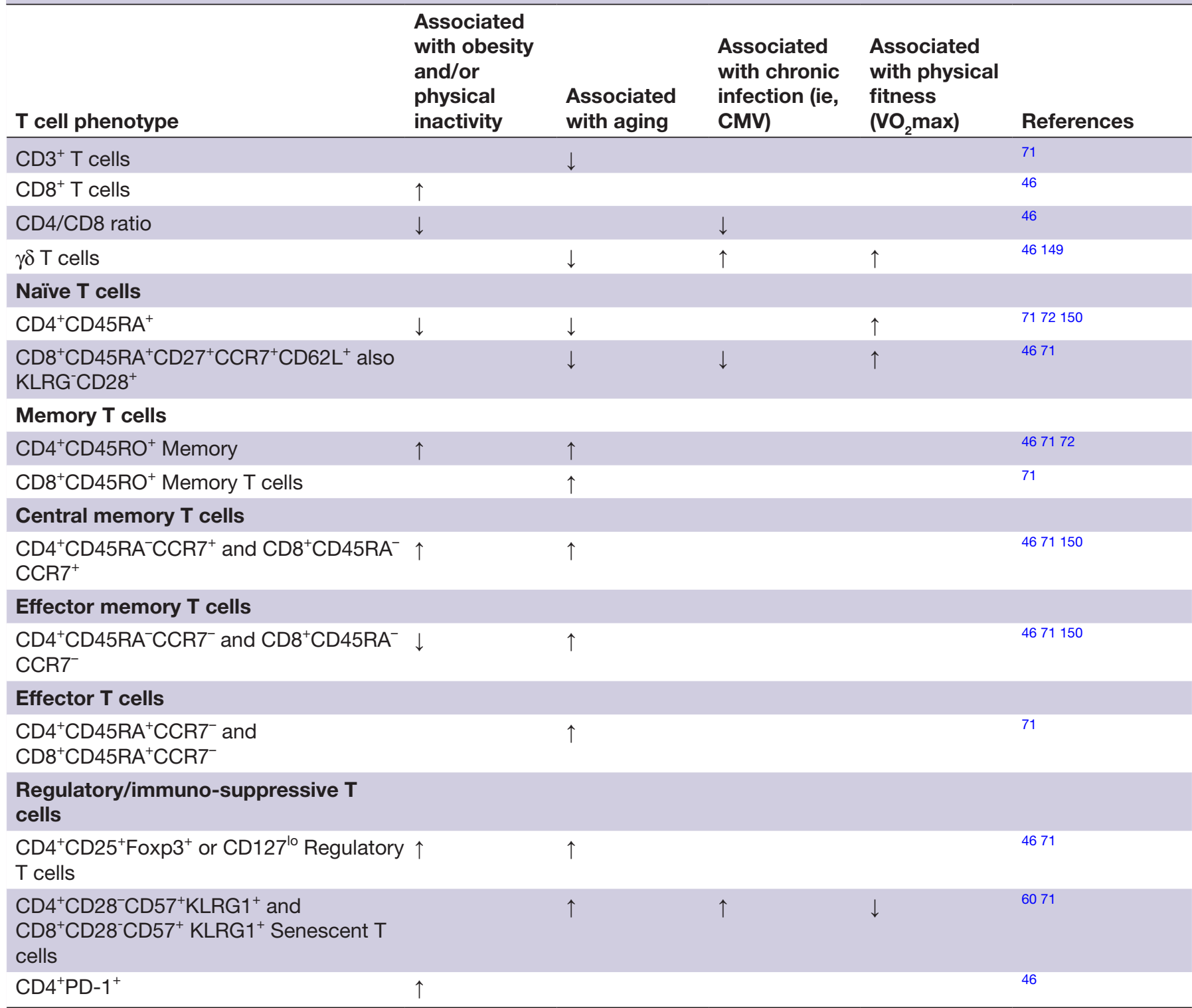

$\uparrow$ indicates condition increases phenotype and $\downarrow$ indicates condition decreases phenotype.

*Indicates phenotype was not improved on in exercise by Duggal et al. ${ }^{71}$

CMV, cytomegalovirus; EMRA, effector memory RA +cells; PBMC, peripheral blood mononuclear cells; $\mathrm{VO}_{2}$ max, maximal oxygen uptake.

T-cells that can be mobilized with exercise, and/or the ability of these cells to traffic toward and infiltrate tumors in xenogeneic mouse models.

\section{Chronic exercise: preserving functional T cells}

Chronic exercise appears to mitigate the detrimental effects on $T$ cells that are caused by a variety of conditions like obesity, aging, and chronic infection. Table 1 lists the phenotypes that can be positively influenced by chronic exercise and phenotypes that have been shown to be correlated with high cardiorespiratory fitness $\left(\mathrm{VO}_{2} \max \right)$. In terms of improving responses to cancer immunotherapy, we hypothesize that chronic exercise could improve antitumor responses in multiple ways. First, chronic exercise is associated with lower proportions of senescent $\mathrm{T}$ cells and increased proportions of naïve $\mathrm{T}$ cells that are needed for optimal immune responses. In a study of over 100 healthy males aged 18-61, our group found a strong association between aerobic fitness $\left(\mathrm{VO}_{2} \max \right)$ and reduced populations of senescent $\mathrm{CD} 8^{+} \mathrm{KLRG1}^{+} \mathrm{CD} 28^{-}$, $\mathrm{CD} 4^{+} \mathrm{KLRG}^{+} \mathrm{CD}^{2} 7^{+}$, and $\mathrm{CD} 8{ }^{+} \mathrm{KLRG}^{+} \mathrm{CD}^{+} 7^{+} \mathrm{T}$ cells. ${ }^{60}$ The loss of CD28 and CD27 and/or the appearance of KLRG1 and CD57 on T cells are indicators of highly differentiated senescent $\mathrm{T}$ cells resulting from chronic antigen stimulation and are a classic feature of the aging immune system. ${ }^{60-63} \mathrm{~T}$ cell senescence is characterized by telomere shortening, impaired IL-2 release, and prolonged DNA damage responses leading to cell cycle arrest. ${ }^{61}$ IL-2 regulates homeostatic maintenance of regulatory $\mathrm{T}$ cells and differentiation of antigen-activated $\mathrm{T}$ cells into effector subsets. ${ }^{64}$ Interestingly, the proliferative defect of 
senescent cells may not be overcome by IL-2 or IL- $15,{ }^{65}$ but IL-7 has been shown to prevent CD27 and CD28 loss, improve proliferation, and restore IL-2 production to $\mathrm{T}$ cells cultured in the presence of tumor cells. ${ }^{66}$ The results from our Spielman et al study reveal that high cardiorespiratory fitness is associated with declines in the accumulation of defective $\mathrm{T}$ cells that have lost their ability to mediate antitumor responses.

Moreover, our group assessed the abundance and distribution of over $30 \mathrm{~T}$ cell phenotypes in sedentary and active men in baseline samples and in response to two types of acute exercise (an incremental maximal cycling test until exhaustion and an endurance cycling test of $45 \mathrm{~min}$ at $60 \%$ of maximum workload) ${ }^{46}$ We found numerous $\mathrm{T}$ cell phenotypes associated with obesity/ lean body mass (Tregs positively correlated with percent body fat) and physical inactivity (elevated $\mathrm{CD} 4^{+}$memory cells and PD- $1^{+}$cells in sedentary individuals) from baseline samples. In addition, we identified two phenotypes that significantly correlated with $\mathrm{VO}_{2} \max ; \delta \delta \mathrm{T}$ cells as a percentage of $\mathrm{CD} 3+\mathrm{T}$ cells, and naïve $\left(\mathrm{CD} 45 \mathrm{RA}^{+} \mathrm{CD} 27^{+} \mathrm{C}-\right.$ D62 $\mathrm{L}^{+} \mathrm{CCR} 7^{+}$) cells as a percentage of total CD8 $+\mathrm{T}$ cells. $\gamma \delta \mathrm{T}$ cells are very responsive to IL-15. On IL-15 exposure, these cells are rapidly activated via upregulation of CD69, HLA-DR, and CD56 expression, secrete high levels of IFN $\gamma$, become highly proliferative, and demonstrate increased cytotoxicity against tumor cells. ${ }^{67}{ }^{68} \mathrm{CD} 4^{-} \mathrm{CD} 8^{-}$ $\mathrm{T}$ cells (or double negative T cells), of which $\gamma \delta \mathrm{T}$ cells comprise a large proportion of these cells, have also been shown to be responsive to IL-15, whereby IL-15 strongly induced their tumoricidal activity through upregulation of effector molecules including NKG2D, DNAM-1, and NKp30 as well as intracellular perforin and granzyme $B$. ${ }^{69}$ Naive CD8 ${ }^{+}$T-cells with a CD45RA ${ }^{+} \mathrm{CD} 27^{+} \mathrm{CD} 62 \mathrm{~L}^{+} \mathrm{CCR} 7^{+}$ phenotype contain a population of long-lived human memory stem-like $\mathrm{T}$ cells $\left(\mathrm{T}_{\mathrm{scm}}\right)$ characterized by additional cell surface markers including the IL-7 receptor- $\alpha$ (CD127), CD95, IL-2R $\beta$ (IL-2 and IL-15 receptor), CXCR3, and LFA-1(70). These cells, which have a naïve cell surface phenotype but have functional attributes of memory cells, have enhanced capacity for self-renewal and a multipotent ability to derive central memory, effector memory and effector $\mathrm{T}$ cells. In a humanized mouse model, $\mathrm{T}_{\mathrm{scm}}$ cells demonstrated superior antitumor activity over other central and effector memory subsets. ${ }^{70}$ Other groups have looked at the influence of chronic exercise on T cell subsets. Duggal et al found higher naive $\mathrm{CD}^{+}, \mathrm{CD}^{+} \mathrm{T}$ cells, and RTE with lower frequencies of effector memory CD45RA+ subsets in old, highly active cyclists compared with aged matched control groups. ${ }^{71}$ Additionally, they found that serum IL-7 and IL-15 levels were higher in older cyclists than both inactive old and young individuals. The percentage of naïve $\mathrm{CD} 4^{+} \mathrm{T}$ cells levels were also correlated to IL-15 serum levels in the active cyclists. ${ }^{72}$ In contrast to the effects of chronic exercise on these myokines, it appears that acute and shortterm training regimens have had inconsistent impacts on changes in myokine levels. A recent longitudinal study in postmenopausal obese women found increased serum levels of the myokines IL- 6 and IL-15 after 12 weeks of both aerobic and resistance exercise training. ${ }^{73}$ In contrast, we did not find changes in serum IL-7 or IL-15 in response to 12 weeks of high intensity interval training or moderate intensity continuous training in women at high risk of breast cancer, although we acknowledge this study is limited by its small sample size and focus only on aerobic training. ${ }^{59}$ Taken together, chronic exercise appears to reshape the $\mathrm{T}$ cell repertoire by reducing dysfunctional $\mathrm{T}$ cells and preserves and/or enhances naive $\mathrm{T}$ cell populations that have high potential to generate immune responses leading to more efficient development of immunological memory. However, more longitudinal studies are needed to examine the effects of exercise training (both aerobic and resistance training) on serum myokine levels and their relationship with exercise-induced modulation of the T-cell compartment.

\section{POTENTIAL MECHANISMS BY WHICH EXERCISE COULD ENHANCE IMMUNOTHERAPY}

The eradication of tumors by the immune system requires a sequential and coordinated immune response. This repetitive series of steps has been termed the CancerImmunity Cycle and is described in more detail by Chen and Mellman. ${ }^{74}$ Successful immunotherapy in patients with cancer requires an intervention to either initiate or boost this process. Although the interactions of dendritic cells and T cells are the most substantial mediators of antitumor responses, other cell types like NK cells are often critical in maintaining tumor control. In animal models, exercise has been shown to have direct antitumor effects on cancer cells via the regulation of the tumor microenvironment (TME) by altering oxygen tension and reduced nutrient availability to slow tumor growth (reviewed by Zhang $e t a l^{75}$ ). These changes may suggest one possible mechanism whereby exercise may improve responses to immunotherapy. In this next section, however, we will specifically outline (with a summary in table 2) yet to be established, although certainly testable, mechanisms by which exercise can augment responses to four major types of immunotherapy.

\section{Immune checkpoint inhibitors}

Immune checkpoint inhibitors comprise a class of drugs in the form of monoclonal antibodies that prevent immune regulatory proteins from turning off immune responses from effector cells. Drugs that target proteins that restrain $\mathrm{T}$ cell activation and/or proliferation like PD-1 and CTLA- 4 are the two most common clinically used checkpoint inhibitors. Two recent studies have demonstrated in animal models that the combination of exercise during anti-PD-1 therapy slowed tumor growth to a greater degree than either modality alone. Wennerberg et al in a breast cancer model found that the incorporation of 30 min of treadmill activity 5 days/week during the course of PD-1 blockade/radiation therapy (RT) 
Table 2 Potential mechanisms that could be employed to improve responses to immunotherapy via exercise

\begin{tabular}{|c|c|c|}
\hline Immunotherapy & Mode of exercise & Potential mechanisms to support immunotherapy \\
\hline \multirow[t]{2}{*}{$\begin{array}{l}\text { Immune checkpoint } \\
\text { inhibitors }\end{array}$} & Acute/training & $\begin{array}{l}\text { Increase in trafficking and homing of T cells to tumors } \\
\text { Increase in T cell activation and proliferation } \\
\text { Reduce infiltration of immunosuppressive myeloid cells to the TME }\end{array}$ \\
\hline & Chronic/long term & $\begin{array}{l}\text { Diminish the presence of senescent } \mathrm{T} \text { cells } \\
\text { Improve } \mathrm{T} \text { cell function and metabolism }\end{array}$ \\
\hline \multirow[t]{2}{*}{$\begin{array}{l}\text { Adoptive, CAR, and } \gamma \delta \\
\mathrm{T} \text { cell Therapies }\end{array}$} & Acute/training & $\begin{array}{l}\text { Increase in T cell numbers, including low frequency viral or antigen specific } \\
\mathrm{T} \text { cells, for ex vivo expansion } \\
\text { Increase in trafficking and homing of T cells to tumors } \\
\text { Increase in T cell activation, proliferation, and cytotoxicity } \\
\text { Enhance persistence of T cells in vivo }\end{array}$ \\
\hline & Chronic/long term & $\begin{array}{l}\text { Maintain homeostatic mechanisms for naïve T cell survival via IL-7 } \\
\text { Enhance persistence of T cells in vivo } \\
\text { Decrease in dysfunctional senescent T cells }\end{array}$ \\
\hline NK Cell Therapies & Chronic/long term & $\begin{array}{l}\text { Prevent obesity-mediated NK cell dysfunction } \\
\text { Enhance persistence of NK cells in vivo }\end{array}$ \\
\hline \multirow{2}{*}{$\begin{array}{l}\text { Cancer vaccines: } \\
\text { Dendritic cells and } \\
\text { acellular }\end{array}$} & Acute/training & $\begin{array}{l}\text { Increase in cell yield from leukapheresis products } \\
\text { Improve efficiency of DC maturation in vivo }\end{array}$ \\
\hline & Chronic/long term & $\begin{array}{l}\text { Improve maintenance of circulating DCs normally lost during aging } \\
\text { Decreased age-related decline in phagocytic activity, antigen presentation, } \\
\text { migratory capacity of DCs }\end{array}$ \\
\hline
\end{tabular}

DCs, dendritic cells; NK, natural killer; TME, tumor microenvironment.

decreased tumor-infiltrating myeloid derived suppressor cells (MDSCs) and increased the infiltration of $\mathrm{CD}^{+} \mathrm{T}$ cells thereby shifting the TME from immunosuppressive to a TME more conducive for effector cell function. Tumor growth was significantly slowed in animals that exercised during anti-PD-1/RT compared with sedentary animals receiving the same anti-PD-1/RT regimen. ${ }^{76}$ In a patient-derived xenograft (PDX) non-small-cell lung cancer model, Martín-Ruiz et al also found that exercise in combination with PD-1 blockade reduce tumor growth exhibited by diminished tumor cell proliferation and increase tumor necrosis. ${ }^{77}$ Interestingly, both studies found that exercise improved immune responses in part by limiting myeloid cell infiltration in the TME. In agreement with another animal breast cancer model, wheel running after the establishment of breast cancer limited the accumulation of MDSCs. ${ }^{78}$ Since both polymorphonuclear MDSCs, monocytic MDSCs, and other immunosuppressive myeloid cells strongly negate responses to cancer immunotherapy ${ }^{79-81}$ exercise may improve immune responses to checkpoint blockade by limiting the effects of these cells. It should be noted that it appears that inactivity and/or obesity may have an opposite effect on the response to checkpoint blockade. In both animal models and human studies, the data suggest that obese individuals with higher BMI actually respond better to checkpoint inhibition. ${ }^{82} 83$ Donnelly et al contend that the impact of BMI on outcomes needs to be carefully scrutinized as many confounding variables (including age, gender, stage, lactate dehydrogenase, performance status, and BRAF mutation status) likely contribute to this phenomenon. ${ }^{84}$ Although the preliminary data on the synergistic effect of exercise and checkpoint inhibition looks promising, the variables outlined by Donnelly et al will also likely influence investigations on the use of adjunct exercise in checkpoint blockade therapies.

\section{Adoptive T cell therapies}

The clinical use of ex vivo expanded $\mathrm{T}$ cells has been a mainstay for cancer immunotherapies for decades. Although it is understood that there are differences in the manufacturing of tumor-infiltrating $\mathrm{T}$ cells, virus specific $\mathrm{T}$ cells, chimeric antigen receptor $\mathrm{T}$ (CAR-T) cells, and $\gamma \delta \mathrm{T}$ cells for therapeutic use, it is likely that the effects of exercise on T cell biology can be applied to each of these treatment modalities. Since acute exercise rapidly mobilizes and increases $\mathrm{T}$ cell numbers in peripheral blood, short bouts of exercise may simply be used to increase the numbers of $\mathrm{T}$ cells collected from leukapheresis procedures. This approach could potentially overcome manufacturing issues like the low cell numbers collected from lymphopenic patients, long culture times to produce sufficient T cells, and/or poor ex vivo expansion of T cells. ${ }^{85-88}$ Acute exercise under some conditions can result in a biphasic response, whereby cell populations can drop below baseline levels in the hours following 
the completion of the exercise. This phenomenon likely reflects a protective effect of immune cells redistributing into various organ sites as part of a response to stress. ${ }^{89} 90$ These mobilized cells have enhanced functional capacities and if harvested before redeployment into tissues, could also provide a superior population of cells for the manufacturing the process. With the improved yields of cells, it is likely that culture times to obtain the desired numbers for dosing can be shortened. Emerging evidence suggests that the antitumor activity of CAR-T cells may be enhanced by shorter culture times. ${ }^{91}$ In addition, short term exercise can improve the collection of low-frequency $\mathrm{T}$ cells like $\gamma \delta \mathrm{T}$ cells, virus-specific $\mathrm{T}$ cells, and antigen specific $\mathrm{T}$ cells.

Prolonged $\mathrm{T}$ cell expansion and persistence in vivo are associated with better clinical outcomes in patients treated with $\mathrm{T}$ cell therapies. ${ }^{92-94}$ We hypothesize, that exercise, both in the acute and the long-term settings, has the potential to significantly improve both the expansion and persistence of $\mathrm{T}$ cells. A connection between exercise and $\mathrm{T}$ cell expansion and persistence is potentially mediated by IL-7 and IL-15. As mentioned previously, skeletal muscle is a major source of IL-7 and IL-15 and the secretion of both are increased after exercise and the elevated levels may improve expansion and persistence in $\mathrm{T}$ cell immunotherapies. Preclinical models have shown that IL-15 and IL-7 contribute to superior CAR-T cell proliferation, effector functions, trafficking, survival, and antitumor activity. ${ }^{95}$ In patients with advanced stage lymphoma treated with CAR-19 T cells, high serum levels of IL-15 were associated with greater peak CAR-T levels in circulation and lymphoma remissions. ${ }^{96}$ One caveat to be noted here, is that a recently published study demonstrated reduced $\mathrm{T}$ cell counts in animal models subjected to 6 weeks of exercise training as a result of declining hematopoiesis. ${ }^{97}$ While it is unknown about how long lasting these effects are, there will need to be some additional scrutiny in cancer patients to confirm and/or account for a potential drop in $\mathrm{T}$ cell counts during a particular bout of exercise or training session. However, the clinical observations in the CAR-T treatment setting provide a very provocative and testable hypothesis that frequent bouts of exercise sustain high levels of IL-7 and IL-15 for optimal expansion and persistence of adoptively transferred T cells. Moreover, by simply engaging in exercise after adoptive transfer therapy, the therapeutic cell products would undergo frequent mobilization and redistribution which is likely to increase their efficacy.

Chronic exercise moderates the effects of the aging immune system and likely augments responses to immunotherapy by preserving naive $\mathrm{T}$ cells, reducing the accumulation of senescent $\mathrm{T}$ cells, and increasing the frequency of stem-cell like memory $\mathrm{T}$ cells. Each of these $\mathrm{T}$ cell populations can impact the manufacturing of $\mathrm{T}$ cells for clinical trials using ACT/CAR-T cells. The higher ratios of naïve $\mathrm{T}$ cells in long-term physically active individuals may be important as high ratios of memory $\mathrm{T}$ cells may potentially cause accelerated differentiation of naïve $\mathrm{T}$ cells into a $\mathrm{KLRG}^{+} \mathrm{CD} 27^{\text {lo }}$ senescent phenotype with diminished antitumor activities. ${ }^{98}$ The presence of dysfunctional senescent $\mathrm{T}$ cells during the manufacturing process could result in lower yield of cells, higher numbers of $\mathrm{T}$ cells with insufficient cytokine and cytotoxic capacities, and inhibition of antigen presentation by dendritic cells. ${ }^{99}$ Finally, our observations that naive CD8 ${ }^{+}$ $\mathrm{T}$ cells were correlated with $\mathrm{VO}_{2}$ max may likely suggest that long-term exercise, via skeletal muscle release of IL-7 and IL-15, promotes higher frequencies of cells highly responsive to initiating durable cellular immunity. In summary, our groups have independently found $\mathrm{T}$ cell populations associated with physical fitness parameters $\left(\mathrm{VO}_{2} \max \right)$, and obesity-related factors (BMI, \% body fat, etc) ${ }^{46} 60$ the findings suggest that the body's primary cells that mediate antitumor immunity are specifically influenced by physical fitness. As such, the emerging hypothesis that exercise may enhance the efficacy of $\mathrm{T}$ cell therapies by restoring the quantity, diversity, and function of $\mathrm{T}$ cell subsets in cancer patients is an exciting premise and warrants further study.

\section{NK cell therapies}

Due to their diverse functions, NK cells have long been considered a desirable form of cellular immunotherapy. ${ }^{100}$ NK cells have performed well clinically in hematologic malignancies and transplant settings. ${ }^{101}$ In other settings, the clinical efficacy of NK cells has been inconsistent with many factors likely contributing to this problem. Manufacturing aspects such as low NK cell quantities in the leukapheresis product and poor ex vivo expansion and/ or activation are significant obstacles. Once infused, the lack of persistence and in vivo expansion appear to be significant determining factors of whether patients will respond. ${ }^{102}$ The collection of a leukapheresis product after acute exercise could potentially solve the manufacturing issues of low yields and ex vivo expansion since the product collected after exercise would contain approximately 5-10 times the amount of primed NK cells compared with routine leukapheresis collections. Exercise can also greatly limit the effects of obesity on NK cells. The excess lipid/fatty acid accumulation causes NK cell dysfunction by directly inhibiting mTOR-mediated glycolysis. ${ }^{103} 104$ Glycolysis and oxidative phosphorylation drive proper NK cell activation and these processes are initiated by cytokines like IL-2, IL-12, and IL-15. ${ }^{105}$ IL-2 and IL-15 result in the upregulation of metabolic regulators mTORC and c-Myc resulting in sustained NK cell survival and great antitumor capacities. ${ }^{106} 107$ Since exercise training has been shown to reduce fatty acid levels in obese/sedentary individuals, ${ }^{108} 109$ chronic exercise can improve NK cell function by limiting the immunosuppressive effect of obesity on NK cells.

\section{Dendritic cell-based cancer vaccines}

Cancer vaccines are used clinically to stimulate the immune system and generate $\mathrm{T}$ cells that can recognize tumor antigens and specifically kill tumor cells that 
express those antigens. Dendritic cells can be targeted in vivo with tumor antigens (ie, peptide injection into the intradermal layer of the skin) or by ex vivo cultured antigen-loaded dendritic cells that can also be injected into the intradermal layer. In vaccines manufactured using dendritic cells, circulating monocytes are obtained from leukapheresis collections, purified most commonly by elutriation or immunomagnetic selection, and then placed into ex vivo culture to differentiate the monocytes into dendritic cells. In the acute setting, exercise can be utilized to increase the yield of monocytes from leukapheresis collections. Since monocytopenia has been observed in patients with a variety of cancers, ${ }^{110} 111$ the lack of adequate quantities of monocytes for the manufacturing of dendritic cell vaccines is a significant issue. We demonstrated a threefold increase in the number of circulating monocytes collected from healthy volunteers after they ran on a treadmill until with increasing intensity until volitional exhaustion. ${ }^{112}$ Monocytes collected after the exercise exhibited similar cell surface phenotypes, maturation efficiency, and antigen uptake to monocytes taken from subjects without exercise. In addition, healthy volunteers that cycled for $20 \mathrm{~min}$ at $80 \%$ of $\mathrm{VO}_{2}$ max in a single bout of acute exercise demonstrated an increase in circulating plasmacytoid dendritic cells are also mobilized during acute exercise. ${ }^{113}$ Chronic exercise may also reduce the presence of immunosuppressive monocytes in cancer patients. The significant accumulation of these cells in peripheral blood resulting from interactions within the TME can affect the quality of dendritic cell maturation in ex vivo cultures. ${ }^{114-116}$ Since patients ith cancer exhibit significant immune dysfunction from the normal aging process and from tumor-derived immunosuppression, physical activity and further exercise training could benefit cancer patients receiving cancer vaccines through the improvement of dendritic cell numbers and enhanced antitumor functions.

\section{INCORPORATION OF EXERCISE INTO CLINICAL APPLICATIONS AND TRANSLATION}

Investigators are increasingly incorporating exercise training and physical activity into practice and in clinical trials to improve quality of life, ${ }^{117-120}$ improve cardiorespiratory function, ${ }^{121-123}$ and even as a preventive and/ or therapeutic anticancer intervention. ${ }^{124}$ Exercise was proposed as an immunotherapy by de Araújo et al as a way to counter immunosenescense in aging cancer patients. ${ }^{125}$ Since then, the concept of using exercise to augment cancer therapy, exercise-oncology, has been progressively advocated. ${ }^{126-128}$ While the field is still in its infancy, data from preclinical animal models as well as human studies are providing insight and sound justification into how clinical trials might be designed to incorporate exercise into immunotherapeutic regimens. For example, the study by Pophali et al provides an excellent model for how to measure the impact of exercise in that the group prospectively measured the physical activity in approximately 3000 newly diagnosed lymphoma patients and found that active patients had improved survival vs more sedentary patients. ${ }^{129} \mathrm{~A}$ similar approach and clinical setting may be applied to ask whether increased physical activity, aerobic capacity, or training programs improve responses to immunotherapy. In order to properly use exercise in the oncology setting, several legitimate concerns including feasibility of incorporating exercise training into existing clinical trials, ensuring safe training regimens in patients who are often frail, and patient compliance, must continue to be addressed by the community. In terms of feasibility, perhaps the best setting to introduce exercise is in newly diagnosed patients who are early in their treatment. For patient compliance, new ways of encouraging compliance are also being implemented as the community better understands barriers to exercise in patients. ${ }^{130-132}$ Finally, more published guidelines are becoming available to clinicians to incorporate physical activity in the treatment of cancer patients. ${ }^{133-135}$ Although the incorporation of exercise into clinical trials for patients appears to be quite feasible and safe, there will be some patients with cancer who are unable to exercise or are too sick for exercise. ${ }^{136-138}$

Another major obstacle to optimizing exercise in the treatment of cancer patients is that it is currently unclear as to what parameters of exercise show the most promise for improving disease outcomes. The FITT principles in exercise are indeed significant and need to be considered as they contribute greatly to the heterogeneity of defining a physiologically effective exercise dose. Dethlefsen et al argue that single bouts of acute exercise are beneficial to the cancer patient, as exercise causes physiological changes, even transiently, that increase the anticancer components of exercise. ${ }^{139} 140$ However, data from the literature suggests that there are considerable differences in outcomes in cancer patients on exercise regimens. There is some evidence that shortterm training $(<4$ months $)$ in patients with cancer does not appear to yield significant benefits on measured outcomes like improved preoperative fitness, aerobic capacity, or chemotherapy completion rates. ${ }^{141-143}$ However, improved cardiorespiratory fitness (VO2max) appears to be one of the most consistent improvements among studies involving cancer patients. ${ }^{144}{ }^{145}$ In noncancer patient populations, there is evidence that the immune system (ie, changes in lymphocyte frequencies) can change in athletes after short-term training programs. ${ }^{146147}$ In patients with rheumatoid arthritis who completed ten weeks of high-intensity interval training, disease severity was reduced, cardiorespiratory function (VO2max) improved, and circulating inflammatory monocytes were reduced. ${ }^{148}$ Moving forward, the data collected from the effects of exercise on cancer patients will be important, as the information will likely guide the design of future studies assessing the impact of exercise on responses to immunotherapy. 


\section{FUTURE DIRECTIONS AND CONCLUSIONS}

It is understood that much of what we have proposed here needs to be investigated and confirmed (or disproved) before exercise be can incorporated routinely into immunotherapeutic regimens. It is clear that there are many complex aspects to the impact of exercise on immune responses. Also, since most human studies have utilized healthy subjects, similar studies will need to be performed in cancer patients in order to better understand whether exercise can restore systemic immunity in cancer patients in which immune suppression is commonly observed. The preliminary evidence is encouraging to support the hypothesis that exercise can improve immunological fitness to the extent that patients should be able to respond better to immunotherapeutic regimens. Now the difficult task has begun to systematically test these hypotheses in both animal models and in clinical trials. It is hoped that the evidence and scientific premise we have outlined here would provide significant justification to move these studies forward.

Contributors MPG and RJS contributed to the conception of the work. All authors contributed to the drafting and revising of the work. All authors provided final approval of the work.

Competing interests No, there are no competing interests.

Patient consent for publication Not required.

Provenance and peer review Not commissioned; externally peer reviewed.

Open access This is an open access article distributed in accordance with the Creative Commons Attribution Non Commercial (CC BY-NC 4.0) license, which permits others to distribute, remix, adapt, build upon this work non-commercially, and license their derivative works on different terms, provided the original work is properly cited, appropriate credit is given, any changes made indicated, and the use is non-commercial. See http://creativecommons.org/licenses/by-nc/4.0/.

\section{REFERENCES}

1 Gustafson MP, Lin Y, LaPlant B, et al. Immune monitoring using the predictive power of immune profiles. $J$ Immunother Cancer 2013;1:7.

2 Spitzer MH, Carmi Y, Reticker-Flynn NE, et al. Systemic immunity is required for effective cancer immunotherapy. Cell 2017;168:487-502.

3 Zuazo M, Arasanz H, Fernández-Hinojal G, et al. Functional systemic CD4 immunity is required for clinical responses to PD-L1/ PD-1 blockade therapy. EMBO Mol Med 2019;11:e10293.

4 Ashcraft KA, Peace RM, Betof AS, et al. Efficacy and mechanisms of aerobic exercise on cancer initiation, progression, and metastasis: a critical systematic review of in vivo preclinical data. Cancer Res 2016;76:4032-50.

5 Lugo D, Pulido AL, Mihos CG, et al. The effects of physical activity on cancer prevention, treatment and prognosis: a review of the literature. Complement Ther Med 2019;44:9-13.

6 Matthews CE, Moore SC, Arem H, et al. Amount and intensity of leisure-time physical activity and lower cancer risk. $J$ Clin Oncol 2020;38:686-97.

7 Rezende LFMde, Sá THde, Markozannes G, et al. Physical activity and cancer: an umbrella review of the literature including 22 major anatomical sites and 770000 cancer cases. Br J Sports Med 2018;52:826-33.

8 Caspersen CJ, Powell KE, Christenson GM. Physical activity, exercise, and physical fitness: definitions and distinctions for health-related research. Public Health Rep 1985;100:126-31.

9 World Health Organization. Physical activity, 2018. Available: http:// www.who.int/dietphysicalactivity/pa/en/

10 Zubin Maslov P, Schulman A, Lavie CJ, et al. Personalized exercise dose prescription. Eur Heart J 2018;39:2346-55.

11 American College of Sports Medicine. ACSM's guidelines for exercise testing and prescription. Lippincott Williams \& Wilkins, 2013.
12 Lansley KE, Dimenna FJ, Bailey SJ, et al. A 'new' method to normalise exercise intensity. Int J Sports Med 2011;32:535-41.

13 Wheatley CM, Kannan T, Bornschlegl S, et al. Conducting maximal and submaximal endurance exercise testing to measure physiological and biological responses to acute exercise in humans. $J$ Vis Exp 2018;140:e58417.

14 Midgley AW, McNaughton LR, Polman R, et al. Criteria for determination of maximal oxygen uptake: a brief critique and recommendations for future research. Sports Med 2007;37:1019-28.

15 Beckers PJ, Possemiers NM, Van Craenenbroeck EM, et al. Comparison of three methods to identify the anaerobic threshold during maximal exercise testing in patients with chronic heart failure. Am J Phys Med Rehabil 2012;91:148-55.

16 American Thoracic Society, American College of Chest Physicians. ATS/ACCP statement on cardiopulmonary exercise testing. Am J Respir Crit Care Med 2003;167:211-77.

17 Strasser B, Burtscher M. Survival of the fittest VO sub 2 sub max a key predictor of longevity. Front Biosci 2018;23:1505-16.

18 Levine BD. .VO2max: what do we know, and what do we still need to know? J Physiol 2008;586:25-34.

19 Boushel R, Gnaiger E, Calbet JAL, et al. Muscle mitochondrial capacity exceeds maximal oxygen delivery in humans. Mitochondrion 2011;11:303-7.

20 Ainsworth BE, Haskell WL, Leon AS, et al. Compendium of physical activities: classification of energy costs of human physical activities. Med Sci Sports Exerc 1993;25:71-80.

21 Wasfy MM, Baggish AL. Exercise dose in clinical practice. Circulation 2016;133:2297-313.

22 Duggal NA, Niemiro G, Harridge SDR, et al. Can physical activity ameliorate immunosenescence and thereby reduce age-related multi-morbidity? Nat Rev Immunol 2019;19:563-72.

23 Gleeson M, Bishop NC, Stensel DJ, et al. The anti-inflammatory effects of exercise: mechanisms and implications for the prevention and treatment of disease. Nat Rev Immunol 2011;11:607-15.

24 Hakim FT, Flomerfelt FA, Boyiadzis M, et al. Aging, immunity and cancer. Curr Opin Immunol 2004;16:151-6.

25 Lavin KM, Perkins RK, Jemiolo B, et al. Effects of aging and lifelong aerobic exercise on basal and exercise-induced inflammation. $J$ Appl Physiol 2020;128:87-99.

26 Simpson RJ, Lowder TW, Spielmann G, et al. Exercise and the aging immune system. Ageing Res Rev 2012;11:404-20.

27 Stoner L, Rowlands D, Morrison A, et al. Efficacy of exercise intervention for weight loss in overweight and obese adolescents: meta-analysis and implications. Sports Med 2016;46:1737-51.

28 Pedersen BK, Febbraio MA. Muscles, exercise and obesity: skeletal muscle as a secretory organ. Nat Rev Endocrinol 2012;8:457-65.

29 Bortoluzzi S, Scannapieco P, Cestaro A, et al. Computational reconstruction of the human skeletal muscle secretome. Proteins 2006;62:776-92.

30 Fischer CP. Interleukin-6 in acute exercise and training: what is the biological relevance? Exerc Immunol Rev 2006;12:6-33.

31 Shephard RJ. Cytokine responses to physical activity, with particular reference to IL-6: sources, actions, and clinical implications. Crit Rev Immunol 2002;22:165-82.

32 Pedersen BK, Febbraio MA. Muscle as an endocrine organ: focus on muscle-derived interleukin-6. Physiol Rev 2008;88:1379-406.

33 Fiuza-Luces C, Santos-Lozano A, Joyner M, et al. Exercise benefits in cardiovascular disease: beyond attenuation of traditional risk factors. Nat Rev Cardiol 2018;15:731-43.

34 Quinn LS, Haugk KL, Grabstein KH. Interleukin-15: a novel anabolic cytokine for skeletal muscle. Endocrinology 1995;136:3669-72.

35 Haugen F, Norheim F, Lian H, et al. II-7 is expressed and secreted by human skeletal muscle cells. Am J Physiol Cell Physiol 2010;298:C807-16.

36 Nielsen AR, Mounier R, Plomgaard P, et al. Expression of interleukin-15 in human skeletal muscle effect of exercise and muscle fibre type composition. J Physiol 2007;584:305-12.

37 Tamura Y, Watanabe K, Kantani T, et al. Upregulation of circulating IL-15 by treadmill running in healthy individuals: is IL-15 an endocrine mediator of the beneficial effects of endurance exercise? Endocr J 2011;58:211-5.

38 Fry TJ, Mackall CL. The many faces of IL-7: from lymphopoiesis to peripheral T cell maintenance. J Immunol 2005;174:6571-6.

39 Goldrath AW, Sivakumar PV, Glaccum M, et al. Cytokine requirements for acute and basal homeostatic proliferation of naive and memory CD8+ T cells. J Exp Med 2002;195:1515-22.

40 Wu J, Weisshaar N, Hotz-Wagenblatt A, et al. Skeletal muscle antagonizes antiviral $\mathrm{CD} 8^{+} \mathrm{T}$ cell exhaustion. Sci Adv 2020;6:eaba3458. 
41 Wallace DL, Bérard M, Soares MVD, et al. Prolonged exposure of naïve CD8+ T cells to interleukin-7 or interleukin-15 stimulates proliferation without differentiation or loss of telomere length. Immunology 2006;119:243-53.

42 Cieri N, Camisa B, Cocchiarella F, et al. II-7 and IL-15 instruct the generation of human memory stem T cells from naive precursors. Blood 2013;121:573-84.

43 Pfefferle A, Jacobs B, Haroun-Izquierdo A, et al. Deciphering natural killer cell homeostasis. Front Immunol 2020;11:812.

44 Nelke C, Dziewas R, Minnerup J, et al. Skeletal muscle as potential central link between sarcopenia and immune senescence. EBioMedicine 2019;49:381-8.

45 Simpson RJ, Kunz H, Agha N, et al. Exercise and the regulation of immune functions. Prog Mol Biol Trans/ Sci 2015;135:355-80.

46 Gustafson MP, DiCostanzo AC, Wheatley CM, et al. A systems biology approach to investigating the influence of exercise and fitness on the composition of leukocytes in peripheral blood. $J$ Immunother Cancer 2017;5:30.

47 Rooney BV, Bigley AB, LaVoy EC, et al. Lymphocytes and monocytes egress peripheral blood within minutes after cessation of steady state exercise: a detailed temporal analysis of leukocyte extravasation. Physiol Behav 2018;194:260-7.

48 Bigley AB, Rezvani K, Chew C, et al. Acute exercise preferentially redeploys NK-cells with a highly-differentiated phenotype and augments cytotoxicity against lymphoma and multiple myeloma target cells. Brain Behav Immun 2014;39:160-71.

49 LaVoy EC, Hussain M, Reed J, et al. T-Cell redeployment and intracellular cytokine expression following exercise: effects of exercise intensity and cytomegalovirus infection. Physiol Rep 2017; 5:e13070.

50 LaVoy EC, Bosch JA, Lowder TW, et al. Acute aerobic exercise in humans increases cytokine expression in CD27(-) but not CD27(+) CD8(+) T-cells. Brain Behav Immun 2013;27:54-62.

51 Baker FL, Bigley AB, Agha NH, et al. Systemic $\beta$-Adrenergic Receptor Activation Augments the ex vivo Expansion and AntiTumor Activity of V $9 \mathrm{~V} \delta 2$ T-Cells. Front Immunol 2019;10:3082.

52 Simpson RJ, Bigley AB, Agha N, et al. Mobilizing immune cells with exercise for cancer immunotherapy. Exerc Sport Sci Rev 2017:45:163-72.

53 Dhabhar FS. Effects of stress on immune function: the good, the bad, and the beautiful. Immunol Res 2014:58:193-210.

54 Edwards KM, Burns VE, Carroll D, et al. The acute stressinduced immunoenhancement hypothesis. Exerc Sport Sci Rev 2007;35:150-5

55 Pedersen L, Idorn M, Olofsson GH, et al. Voluntary running suppresses tumor growth through epinephrine- and IL-6-dependent NK cell mobilization and redistribution. Cell Metab 2016:23:554-62.

56 LaVoy ECP, Bollard CM, Hanley PJ, et al. A single bout of dynamic exercise enhances the expansion of MAGE-A4 and PRAMEspecific cytotoxic T-cells from healthy adults. Exerc Immunol Rev 2015;21:144-53.

57 Woods JA, Ceddia MA, Wolters BW, et al. Effects of 6 months of moderate aerobic exercise training on immune function in the elderly. Mech Ageing Dev 1999;109:1-19.

58 Campbell PT, Wener MH, Sorensen B, et al. Effect of exercise on in vitro immune function: a 12-month randomized, controlled trial among postmenopausal women. J Appl Physio 2008;104:1648-55

59 Coletta AM, Agha NH, Baker FL, et al. The impact of high-intensity interval exercise training on NK-cell function and circulating myokines for breast cancer prevention among women at high risk for breast cancer. Breast Cancer Res Treat 2021. doi:10.1007/ s10549-021-06111-z. [Epub ahead of print: 08 Feb 2021].

60 Spielmann G, McFarlin BK, O'Connor DP, et al. Aerobic fitness is associated with lower proportions of senescent blood T-cells in man. Brain Behav Immun 2011;25:1521-9.

61 Akbar AN, Henson SM. Are senescence and exhaustion intertwined or unrelated processes that compromise immunity? Nat Rev Immunol 2011;11:289-95.

62 Henson SM, Franzese O, Macaulay R, et al. Klrg1 signaling induces defective Akt (Ser473) phosphorylation and proliferative dysfunction of highly differentiated CD8+ T cells. Blood 2009;113:6619-28.

63 Thimme R, Appay V, Koschella M, et al. Increased expression of the NK cell receptor KLRG1 by virus-specific CD8 T cells during persistent antigen stimulation. J Virol 2005;79:12112-6.

64 Boyman O, Sprent J. The role of interleukin-2 during homeostasis and activation of the immune system. Nat Rev Immunol 2012:12:180-90.

65 Brenchley JM, Karandikar NJ, Betts MR, et al. Expression of CD57 defines replicative senescence and antigen-induced apoptotic death of CD8+ T cells. Blood 2003;101:2711-20.
66 Zhang Y, Pfannenstiel LW, Bolesta E, et al. Interleukin-7 inhibits tumor-induced CD27-CD28- suppressor T cells: implications for cancer immunotherapy. Clin Cancer Res 2011;17:4975-86.

67 Van Acker HH, Anguille S, Willemen Y, et al. Interleukin-15 enhances the proliferation, stimulatory phenotype, and antitumor effector functions of human gamma delta T cells. J Hematol Oncol 2016;9:101.

68 García VE, Jullien D, Song M, et al. IL-15 enhances the response of human gamma delta $T$ cells to nonpeptide [correction of nonpetide] microbial antigens. J Immunol 1998:160:4322-9.

69 Yao J, Ly D, Dervovic D, et al. Human double negative T cells target lung cancer via ligand-dependent mechanisms that can be enhanced by IL-15. J Immunother Cancer 2019;7:17.

70 Gattinoni L, Lugli E, Ji Y, et al. A human memory T cell subset with stem cell-like properties. Nat Med 2011:17:1290-7.

71 Duggal NA, Pollock RD, Lazarus NR, et al. Major features of immunesenescence, including reduced thymic output, are ameliorated by high levels of physical activity in adulthood. Aging Cell 2018;17:e12750.

72 Bartlett DB, Duggal NA. Moderate physical activity associated with a higher naïve/memory T-cell ratio in healthy old individuals: potential role of IL15. Age Ageing 2020;49:368-73.

73 Kang S, Park IB, Lim ST. Changes levels of myokines after aerobic training and resistance training in post-menopausal females with obesity: a randomized controlled trial. Research Square 2020.

74 Chen DS, Mellman I. Oncology meets immunology: the cancerimmunity cycle. Immunity 2013;39:1-10.

75 Zhang X, Ashcraft KA, Betof Warner A, et al. Can exercise-induced modulation of the tumor physiologic microenvironment improve antitumor immunity? Cancer Res 2019;79:2447-56.

76 Wennerberg E, Lhuillier C, Rybstein MD, et al. Exercise reduces immune suppression and breast cancer progression in a preclinical model. Oncotarget 2020;11:452-61.

77 Martín-Ruiz A, Fiuza-Luces C, Rincón-Castanedo C, et al. Benefits of exercise and immunotherapy in a murine model of human nonsmall-cell lung carcinoma. Exerc Immunol Rev 2020;26:100-15.

78 Garritson J, Krynski L, Haverbeck L, et al. Physical activity delays accumulation of immunosuppressive myeloid-derived suppressor cells. PLoS One 2020;15:e0234548.

$79 \mathrm{Kim}$ IS, Gao Y, Welte T, et al. Immuno-subtyping of breast cancer reveals distinct myeloid cell profiles and immunotherapy resistance mechanisms. Nat Cell Biol 2019;21:1113-26.

80 Mengos AE, Gastineau DA, Gustafson MP. The CD14 ${ }^{+} \mathrm{HLA}-$ $\mathrm{DR}^{\text {lo/neg }}$ Monocyte: An Immunosuppressive Phenotype That Restrains Responses to Cancer Immunotherapy. Front Immunol 2019;10:1147.

81 Weber R, Fleming V, Hu X, et al. Myeloid-Derived suppressor cells hinder the anti-cancer activity of immune checkpoint inhibitors. Front Immunol 2018:9:1310.

82 McQuade JL, Daniel CR, Hess KR, et al. Association of body-mass index and outcomes in patients with metastatic melanoma treated with targeted therapy, immunotherapy, or chemotherapy: a retrospective, multicohort analysis. Lancet Oncol 2018:19:310-22.

83 Wang Z, Aguilar EG, Luna Jl, et al. Paradoxical effects of obesity on T cell function during tumor progression and PD-1 checkpoint blockade. Nat Med 2019;25:141-51.

84 Donnelly D, Bajaj S, Yu J, et al. The complex relationship between body mass index and response to immune checkpoint inhibition in metastatic melanoma patients. J Immunother Cancer 2019;7:222

85 Hutt D, Bielorai B, Baturov B, et al. Feasibility of leukapheresis for CAR T-cell production in heavily pre-treated pediatric patients. Transfus Apher Sci 2020;59:102769.

86 Korell F, Laier S, Sauer S, et al. Current challenges in providing good leukapheresis products for manufacturing of CAR-T cells for patients with relapsed/refractory NHL or all. Cells 2020;9:1225.

87 Tuazon SA, Li A, Gooley T, et al. Factors affecting lymphocyte collection efficiency for the manufacture of chimeric antigen receptor T cells in adults with B-cell malignancies. Transfusion 2019;59:1773-80.

88 Allen ES, Stroncek DF, Ren J, et al. Autologous lymphapheresis for the production of chimeric antigen receptor T cells. Transfusion 2017;57:1133-41.

89 Campbell JP, Turner JE. Debunking the myth of exerciseinduced immune suppression: redefining the impact of exercise on immunological health across the lifespan. Front Immunol 2018;9:648.

90 Simpson RJ, Campbell JP, Gleeson M, et al. Can exercise affect immune function to increase susceptibility to infection? Exerc Immunol Rev 2020;26:8-22. 
91 Ghassemi S, Nunez-Cruz S, O'Connor RS, et al. Reducing Ex Vivo Culture Improves the Antileukemic Activity of Chimeric Antigen Receptor (CAR) T Cells. Cancer Immunol Res 2018;6:1100-9.

92 Porter DL, Hwang W-T, Frey NV, et al. Chimeric antigen receptor T cells persist and induce sustained remissions in relapsed refractory chronic lymphocytic leukemia. Sci Trans/ Med 2015;7:303ra139.

93 Louis CU, Savoldo B, Dotti G, et al. Antitumor activity and long-term fate of chimeric antigen receptor-positive T cells in patients with neuroblastoma. Blood 2011;118:6050-6.

94 Rosenberg SA, Yang JC, Sherry RM, et al. Durable complete responses in heavily pretreated patients with metastatic melanoma using T-cell transfer immunotherapy. Clin Cancer Res 2011;17:4550-7.

95 Xu Y, Zhang M, Ramos CA, et al. Closely related T-memory stem cells correlate with in vivo expansion of CAR.CD19-T cells and are preserved by IL-7 and IL-15. Blood 2014;123:3750-9.

96 Kochenderfer JN, Somerville RPT, Lu T, et al. Lymphoma remissions caused by anti-CD19 chimeric antigen receptor T cells are associated with high serum interleukin-15 levels. $J$ Clin Oncol 2017:35:1803-13

97 Frodermann V, Rohde D, Courties G, et al. Exercise reduces inflammatory cell production and cardiovascular inflammation via instruction of hematopoietic progenitor cells. Nat Med 2019;25:1761-71

98 Klebanoff CA, Scott CD, Leonardi AJ, et al. Memory T cell-driven differentiation of naive cells impairs adoptive immunotherapy. J Clin Invest 2016;126:318-34.

99 Huff WX, Kwon JH, Henriquez M, et al. The evolving role of CD8+CD28- Immunosenescent T cells in cancer immunology. Int $J$ Mol Sci 2019;20:2810.

100 Woan KV, Miller JS. Harnessing natural killer cell antitumor immunity: from the bench to bedside. Cancer Immunol Res 2019;7:1742-7.

101 Tanaka J, Miller JS. Recent progress in and challenges in cellular therapy using NK cells for hematological malignancies. Blood Rev 2020;44:100678.

102 Rezvani K, Rouce RH. The application of natural killer cell immunotherapy for the treatment of cancer. Front Immunol 2015;6:578.

103 Viel S, Besson L, Charrier E, et al. Alteration of natural killer cell phenotype and function in obese individuals. Clin Immunol 2017;177:12-17.

104 Michelet X, Dyck L, Hogan A, et al. Metabolic reprogramming of natural killer cells in obesity limits antitumor responses. Nat Immunol 2018;19:1330-40.

105 O'Brien KL, Finlay DK. Immunometabolism and natural killer cell responses. Nat Rev Immunol 2019;19:282-90.

106 Kedia-Mehta N, Choi C, McCrudden A, et al. Natural killer cells integrate signals received from tumour interactions and IL2 to induce robust and prolonged anti-tumour and metabolic responses. Immunometabolism 2019;1:e190014.

107 Mao Y, van Hoef V, Zhang X, et al. II-15 activates mTOR and primes stress-activated gene expression leading to prolonged antitumor capacity of NK cells. Blood 2016;128:1475-89.

108 Johnson NA, Sachinwalla T, Walton DW, et al. Aerobic exercise training reduces hepatic and visceral lipids in obese individuals without weight loss. Hepatology 2009;50:1105-12.

109 Shojaee-Moradie F, Baynes KCR, Pentecost C, et al. Exercise training reduces fatty acid availability and improves the insulin sensitivity of glucose metabolism. Diabetologia 2007;50:404-13.

110 Chavan R, Salvador D, Gustafson MP, et al. Untreated stage IV melanoma patients exhibit abnormal monocyte phenotypes and decreased functional capacity. Cancer Immunol Res 2014;2:241-8.

111 Saeed L, Patnaik MM, Begna KH, et al. Prognostic relevance of lymphocytopenia, Monocytopenia and lymphocyte-to-monocyte ratio in primary myelodysplastic syndromes: a single center experience in 889 patients. Blood Cancer J 2017;7:e550

112 LaVoy ECP, Bollard CM, Hanley PJ, et al. A single bout of dynamic exercise by healthy adults enhances the generation of monocytederived-dendritic cells. Cell Immunol 2015;295:52-9.

113 Brown FF, Campbell JP, Wadley AJ, et al. Acute aerobic exercise induces a preferential mobilisation of plasmacytoid dendritic cells into the peripheral blood in man. Physiol Behav 2018:194:191-8.

114 Gustafson MP, Lin Y, Bleeker JS, et al. Intratumoral CD14+ cells and circulating CD14+HLA-DRlo/neg monocytes correlate with decreased survival in patients with clear cell renal cell carcinoma. Clin Cancer Res 2015;21:4224-33.

115 Laborde RR, Lin Y, Gustafson MP, et al. Cancer Vaccines in the World of Immune Suppressive Monocytes (CD14(+)HLA-DR(Io/ neg) Cells): The Gateway to Improved Responses. Front Immunol 2014:5:147.
116 Parney IF, Gustafson MP, Solseth M, et al. Novel strategy for manufacturing autologous dendritic cell/allogeneic tumor lysate vaccines for glioblastoma. Neurooncol Adv 2020;2:vdaa105.

117 Quist M, Langer SW, Lillelund C, et al. Effects of an exercise intervention for patients with advanced inoperable lung cancer undergoing chemotherapy: a randomized clinical trial. Lung Cancer 2020;145:76-82.

118 Koutoukidis DA, Land J, Hackshaw A, et al. Fatigue, quality of life and physical fitness following an exercise intervention in multiple myeloma survivors (MASCOT): an exploratory randomised phase 2 trial utilising a modified Zelen design. $\mathrm{Br} \mathrm{J}$ Cancer 2020;123:187-95.

119 Bekhet AH, Abdallah AR, Ismail HM, et al. Benefits of aerobic exercise for breast cancer survivors: a systematic review of randomized controlled trials. Asian Pac J Cancer Prev 2019;20:3197-209.

120 Kneis S, Wehrle A, Müller J, et al. It's never too late - balance and endurance training improves functional performance, quality of life, and alleviates neuropathic symptoms in cancer survivors suffering from chemotherapy-induced peripheral neuropathy: results of a randomized controlled trial. BMC Cancer 2019;19:414.

121 Howden EJ, Bigaran A, Beaudry R, et al. Exercise as a diagnostic and therapeutic tool for the prevention of cardiovascular dysfunction in breast cancer patients. Eur J Prev Cardiol 2019;26:305-15

122 Scott JM, Zabor EC, Schwitzer E, et al. Efficacy of exercise therapy on cardiorespiratory fitness in patients with cancer: a systematic review and meta-analysis. J Clin Oncol 2018;36:2297-305.

123 Foulkes SJ, Howden EJ, Antill Y, et al. Exercise as a diagnostic and therapeutic tool for preventing cardiovascular morbidity in breast cancer patients- the breast cancer exercise intervention (Brexit) trial protocol. BMC Cancer 2020;20:655.

124 lyengar NM, Jones LW. Development of exercise as interception therapy for cancer: a review. JAMA Oncol 2019;5:1620.

125 de Araújo AL, Silva LCR, Fernandes JR, et al. Preventing or reversing immunosenescence: can exercise be an immunotherapy? Immunotherapy 2013;5:879-93.

126 Ashcraft KA, Warner AB, Jones LW, et al. Exercise as adjunct therapy in cancer. Semin Radiat Oncol 2019;29:16-24.

127 Holmen Olofsson G, Jensen AWP, Idorn M, et al. Exercise oncology and Immuno-Oncology; a (future) dynamic Duo. Int J Mol Sci 2020;21:3816.

128 Jones LW, Alfano CM. Exercise-oncology research: past, present, and future. Acta Oncol 2013;52:195-215.

129 Pophali PA, Ip A, Larson MC, et al. The association of physical activity before and after lymphoma diagnosis with survival outcomes. Am J Hematol 2018;93:1543-50.

130 Turner RR, Steed L, Quirk H, et al. Interventions for promoting habitual exercise in people living with and beyond cancer. Cochrane Database Syst Rev 2018;9:Cd010192.

131 Avancini A, Skroce K, Tregnago D, et al. "Running with cancer": A qualitative study to evaluate barriers and motivations in running for female oncological patients. PLoS One 2020;15:e0227846.

132 Sallis R, Franklin B, Joy L, et al. Strategies for promoting physical activity in clinical practice. Prog Cardiovasc Dis 2015;57:375-86.

133 Schmitz KH, Campbell AM, Stuiver MM, et al. Exercise is medicine in oncology: engaging clinicians to help patients move through cancer. CA Cancer J Clin 2019;69:468-84.

134 Cormie P, Trevaskis M, Thornton-Benko E, et al. Exercise medicine in cancer care. Aust J Gen Pract 2020;49:169-74.

135 Patel AV, Friedenreich CM, Moore SC, et al. American College of sports medicine roundtable report on physical activity, sedentary behavior, and cancer prevention and control. Med Sci Sports Exerc 2019;51:2391-402.

136 Segal R, Zwaal C, Green E, et al. Exercise for people with cancer: a clinical practice guideline. Curr Oncol 2017;24:40-6.

137 Hayes SC, Newton RU, Spence RR, et al. The exercise and sports science Australia position statement: exercise medicine in cancer management. J Sci Med Sport 2019;22:1175-99.

138 Ni H-J, Pudasaini B, Yuan X-T, et al. Exercise training for patients pre- and Postsurgically treated for non-small cell lung cancer: a systematic review and meta-analysis. Integr Cancer Ther 2017;16:63-73.

139 Dethlefsen C, Lillelund C, Midtgaard J, et al. Exercise regulates breast cancer cell viability: systemic training adaptations versus acute exercise responses. Breast Cancer Res Treat 2016;159:469-79.

140 Dethlefsen C, Pedersen KS, Hojman P. Every exercise bout matters: linking systemic exercise responses to breast cancer control. Breast Cancer Res Treat 2017;162:399-408. 
141 Karenovics W, Licker M, Ellenberger C, et al. Short-term preoperative exercise therapy does not improve long-term outcome after lung cancer surgery: a randomized controlled study. Eur $J$ Cardiothorac Surg 2017:52:47-54.

142 Mijwel S, Bolam KA, Gerrevall J, et al. Effects of exercise on chemotherapy completion and hospitalization rates: the OptiTrain breast cancer trial. Oncologist 2020;25:23-32.

143 Boereboom CL, Blackwell JEM, Williams JP, et al. Short-Term pre-operative high-intensity interval training does not improve fitness of colorectal cancer patients. Scand J Med Sci Sports 2019;29:1383-91.

144 Jones LW, Liang Y, Pituskin EN, et al. Effect of exercise training on peak oxygen consumption in patients with cancer: a meta-analysis. Oncologist 2011;16:112-20.

145 Hornsby WE, Douglas PS, West MJ, et al. Safety and efficacy of aerobic training in operable breast cancer patients receiving neoadjuvant chemotherapy: a phase II randomized trial. Acta Oncol 2014;53:65-74.
146 Teixeira AM, Rama L, Carvalho HM, et al. Changes in naïve and memory T-cells in elite swimmers during a winter training season. Brain Behav Immun 2014;39:186-93.

147 Rama L, Teixeira AM, Matos A, et al. Changes in natural killer cell subpopulations over a winter training season in elite swimmers. Eur J Appl Physiol 2013;113:859-68.

148 Bartlett DB, Willis LH, Slentz CA, et al. Ten weeks of high-intensity interval walk training is associated with reduced disease activity and improved innate immune function in older adults with rheumatoid arthritis: a pilot study. Arthritis Res Ther 2018;20:127.

149 Pistillo M, Bigley AB, Spielmann G, et al. The effects of age and viral serology on $\gamma \delta$ T-cell numbers and exercise responsiveness in humans. Cell Immunol 2013;284:91-7.

150 Minuzzi LG, Rama L, Chupel MU, et al. Effects of lifelong training on senescence and mobilization of $\mathrm{T}$ lymphocytes in response to acute exercise. Exerc Immunol Rev 2018;24:72-84. 